\title{
Aproximación a los niveles de alfabetización en la provincia de Cádiz: las poblaciones de Cádiz, El Puerto de Santa María, Medina Sidonia y Alcalá de los Gazules entre 1675 y 1800
}

\section{MARÍA JOSÉ DE LA PASCUA SÁNCHEZ Universidad de Cádiz}

Adentrarse en el tema de la alfabetización en una población determinada (niveles globales y diferenciales, ritmos de evolución, binomio alfabetización tardía/temprana), significa situarse en el horizonte de una serie de cambios cuya trascendencia es mayor de lo que a primera vista pudiera parecer. El paso de una cultura oral y visual a la cultura escrita supone algo más que una modificación del medio a través del cual se produce la información. El modo en que la cultura se transmite acaba conformando e imponiendo su "diktat" a la propia cultura. Modificaciones pues del medio, del objeto mismo, pero también modificaciones en el sujeto o sujetos que intervienen. No resulta difícil imaginarse cómo ha afectado a los hombres y a sus relaciones entre sí, a su universo mental y a sus costumbres, la sustitución de unas formas concretas de recepción de la instrucción - imágenes, ceremonias y espectáculos, lenguaje hablado- por otras - el libro, fundamentalmente-. En este sentido, desde hace varios años, se viene insistiendo en la importancia que tiene para el Occidente Moderno el desarrollo tecnológico-industrial de la imprenta; la llamada "Revolución del libro", origen de una revolución epistemológica (la invención de la Razón Moderna), de una cultura secularizada e incluso de una revolución religiosa cual es la Reforma Protestante (1). Sin embargo, a pesar de la importancia de estos aspectos, así como de las posibles repercusiones económicas de un tardío acceso a la cultura escrita $-\mathrm{y}$, por tanto, a las novedades científicas y técnicas-

(1) Cfr. al respecto, C. MOYA, «Introducción» al Leviatán de T. Hobbes. Madrid, 1983. 
por parte de determinadas sociedades, nuestro objetivo en este artículo es simplemente una primera aproximación al tema en un marco geográfico y temporal reducido: algunas poblaciones de la provincia de Cádiz entre 1675 y 1800 .

Est'́t aproximación va a ser esencialmente cuantitativa como punto de partida necesario y obligado para reflexiones más aquilatadas y exquisitas; y en ella, además, se va a prescindir de la tradicional discusión acerca de las definiciones sobre alfabetismo y analfabetismo, y la bondad o no de ciertos indicadores de alfabetización. Somos conscientes de la dificultad de trazar una línea divisoria nítida entre alfabetos y analfabetos y es que, como afirma C.M. Cipolla, entre unos y otros hay todo un ejército de semianalfabetos (2); pero - dejando claro que nos merece la consideración de analfabeto- aquella persona que no es capaz de escribir su nombre y que utilizamos la firma como indicador de alfabetización, nadie puede llamarse a engaño.

La valoración cuantitativa de los avances de la alfabetización ha chocado durante mucho tiempo con la problemática de las fuentes. Habida cuenta de la imposibilidad de encontrar fuentes directas para la época moderna, el historiador ha tenido que recurrir a diverso tipo de documentación cuya característica común suele ser la de que un número variable de personas han de firmar obligatoriamente. La elaboración de estadísticas sobre niveles de alfabetización se ha visto favorecida en el caso de Francia (3) e Inglaterra por la existencia, desde el siglo XVII, de registros parroquiales de matrimonios firmados por los contrayentes, si bien en este último país se ha completado la información procedente de éstos con otro tipo de documentación más específica (4). Para el caso de España, B. Bennassar selecciona tres tipos de fuentes (fiscales, judiciales, y notariales), subrayando las ventajas y los inconvenientes de cada una de ellas (5). Las expectativas que a primera vista suscita la docu-

(2) Aquellos que saben leer pero no escribir, y los que saben leer y escribir pero difícilmente entienden lo que leen y escriben algo más que su propio nombre, en $E d u-$ cación y desarrollo en Occidente, Barcelona, 1970, p. 11.

(3) M. FLEURY y P. VALMARY, "Les progrès de l'instruction élémentaire de Louis XIV à Napoléon d'après l'enquête de L. Maggiolo (1877-1879)», Population, 12, (genmar 1957), pp. 71-92.

(4) L. STONE utiliza registros de firmas relativos al juramento de lealtad al Parlamento en 1642, para averiguar el nivel de población alfabeta en vísperas de la guerra civil, y los registros matrimoniales para el período posterior (1642-1840), «Literacy and Education in England 1640-1900», Past and Present, 42, (1969), pp. 69-139.

(5) B. BENNASSAR, "Las resistencias mentales", Origenes del atraso económico español, siglos XVI-XIX, Barcelona, 1985, pp. 147-163. 
mentación referente a procesos inquisitoriales, por la inclusión de un cuestionario cultural bastante completo que se presenta a los acusados, se ven disminuidas por la débil representatividad de la muestra en cuestión, y el análisis del nivel de firmas entre los testigos de los procesos -único dato cultural seriado que se encuentra para éstos- (6), aunque en menor grado, también plantea problemas de este tipo. La fiabilidad de la documentación! fiscal como la procedente de los "donativos" es cuestionable, asimismo, por lo menos para ciertas regiones, tal es el caso de la nuestra, según ha subrayado Bennassar (7) y tendremos ocasión de comprobar. La documentación notarial, por último, tampoco es ninguna panacea, sin embargo, y por lo que se refiere a la escritura concreta que hemos utilizado - el testamento--, reúne a nuestro entender una serie de condiciones que la hacen especialmente apta para este tipo de estudio.

La razón fundamental por la que se insiste en las posibilidades que ofrecen los protocolos notariales al respecto, y que ya fue puesta de manifiesto por F. Furet (8), es la abundancia de estas escrituras y la implicación de amplias capas de población en ellas, con lo que la virtualidad de establecer series continuas a lo largo del tiempo, de contrastar diversos medios geográficos y de obtener muestras representativas queda garantizada, al menos en principio. La fiabilidad de la información obtenida dependerá del mayor o menor cuidado que el notario de turno haya puesto en la redacción y en la conservación del registro, del paso del tiempo y, como no, de la escritura o escrituras elegidas para la muestra, tanto del tipo y del número como del sistema del muestreo. Por lo que se refiere a nuestro apoyo documental concreto, lo constituyen 2351 escrituras testamentarias (que nos suministran 2446 casos analizables, teniendo en cuenta sólo a los otorgantes de las mismas), procedentes de las escribanías de Cádiz, El Puerto de Santa María, Medina Sidonia y Alcalá de los Gazules. Para su recopilación se ha recurrido a un sondeo por el sistema de cortes horizontales cada 25 años, incluyendo las dos fechas límites, que nos va a permitir ofrecer no sólo una visión estática del nivel de alfabetización, sino también seguir la evolución de éste a lo largo del siglo XVIII.

(6) M. C. RODRÍGUEZ y B. BENNASSAR, "Signatures et niveau culturel des témoins et accusès dans les procés d'Inquisition du ressort du Tribunal de Tolède (1525-1817) et du ressort du Tribunal de Cordove (1595-1632)», Caravelle, 31, (1978), pp. 17-46.

(7) B. BENNASSAR, "Las resistencias mentales...» op. cit., p. 154.

(8) F. FURET, "L'histoire quantitative et la construction du fait historique", Annales E.S.C., 1, (1971), pp. 63-82. 
En otro lugar nos hemos extendido sobre la representatividad del testamento gaditano (9), por lo que ahora resumiremos el tema con unas simples notas. En Cádiz, al menos, no puede considerarse al testamento como una fuente elitista, ya que éstos son otorgados por personas de variada extracción social. Están representadas prácticamente todas las profesiones: desde los sirvientes y los trabajadores no cualificados, pasando por los funcionarios, comerciantes y profesiones liberales, hasta rentistas y representantes de la Iglesia y de la oligarquía ciudadana. En este sentido, no es observable una hiperrepresentación de un sector o sectores específicos en detrimento de otros. Tampoco existe un desequilibrio en la representación por sexos, y la proporción entre testadores y testadoras está dentro de los límites de la normalidad. La importancia de ambos aspectos queda manifiesta cuando se considera que, si bien el nivel de instrucción de una sociedad es el resultado de una combinación de factores independientes (10), es evidente que existe una estrecha relación entre nivel de alfabetización y sexo (tradicional analfabetismo de la población femenina) y alfabetización y estructura ocupacional y niveles de renta. Por otra parte, nuestra muestra también nos faculta para profundizar en la tercera variable (11) que es imprescindible tomar en consideración cuando se intenta un estudio de estas características, a saber, el grado de urbanización. En nuestro trabajo se han seleccionado cuatro poblaciones; dos de ellas (Cádiz y El Puerto), situadas en la costa, prototipos de ciudades burguesas; las otras dos (Medina Sidonia y Alcalá de los Gazules), en la campiña gaditana, representan al medio rural. En las dos primeras predomina el sector terciario destacando, por su importancia, el comercio; en las otras dos, la mayoría de su población se dedica a la ganadería y a la agricultura. La posibilidad de establecer contrastes queda así asegurada.

Antes de adentrarse en el análisis de los resultados obtenidos es necesario realizar una indicación más de carácter formal. Debido a que el testamento se otorga, en una gran mayoría de los casos, en condiciones de salud bastante precarias, hemos de jugar con tres posibilidades, a saber, firmó, no firmó porque no sabía y no firmó porque la gravedad de su enfermedad se lo impidió. No hemos querido incluir a los testadores que no firman porque están enfermos dentro del primer grupo, porque si bien

(9) Vivir la muerte en el Cádiz del siglo XVIII: el medio rural y el medio urbano (en prensa), Cádiz, 1989.

(10) C.M. CIPOLLA, Educación y desarrollo, op. cit., p. 19.

(11) Realizamos esta enumeración excluyendo, evidentemente, las dos que están en la base de todas las demás: espacio y tiempo. 
no nos parece probable que tras este comentario se esconda la incapacidad para estampar la firma, al menos masivamente - la mayoría de los testadores afirma no saber escribir-, es preferible mostrarse cautos, considerando, además, que es un grupo que, salvo años excepcionales, no supera el 15 por cien de la muestra. Vayamos ahora con los resultados globales, analizando separadamente cada una de las poblaciones.

En Cádiz capital, las cifras muestran lo poco fiables que resultaban las obtenidas con motivo de la recaudación del donativo de 1635 . Aunque los primeros datos que poseemos son de 40 años más tarde, resulta inverosímil adjudicar a la diferencia de años la divergencia de resultados. Lejos de ese 18,4 por cien que se obtenía para esta capital sobre un total de 1111 donantes (12), es el 61 por cien de la población testamentaria masculina la que firma en 1675 , y la femenina lo hace en el 16,4 por cien de los casos. Además, el resto no es porcentaje de analfabetos (los que afirman no saber son el 27 por cien de los hombres y el 71,76 por cien de las mujeres), sino que se reparte entre éstos, los que dicen no poder hacerlo por la gravedad de su enfermedad -8 por cien-y los indeterminados. Cien años más tarde, en 1775 , firman el 75,7 por cien de los hombres y el 56,8 por cien de las mujeres. Las medias para todo el período (1675-1800), del 56,7 por cien y del 30,5 por cien para hombres y mujeres, respectivamente, esconden esa elevación del nivel de alfabetización que ha tenido lugar, para ambos sexos, en la segunda mitad del Setecientos. Esta progresión ascendente del número de testadores alfabetos sigue, presumiblemente, entre 1775 y 1800 , pero no podemos confirmarlo con cifras puesto que en 1800 , con motivo de la epidemia de fiebre amarilla que está sufriendo Cádiz, el número de testadores imposibilitados para firmar se eleva al 25,3 por cien (en años normales las cifras oscilan entre el 6 por cien y el 9 por cien) y a 15,4 por cien el de testadoras. Las tasas de alfabetización se sitúan pues, para este año, en el 59,2 por cien para los hombres y el 45,5 por cien para las mujeres, muy por debajo de las conseguidas veinticinco años antes.

Aunque, y según se ha comentado ya, el hecho de no incluir entre la población alfabeta a los testadores que no pueden firmar por la gravedad de su enfermedad, hace que los resultados obtenidos estén infravalorados, no hay duda de que los niveles ofrecidos por la población de El Puerto de Santa María son bastante bajos. Las cifras globales para todo el período son del 36,9 por cien de los hombres que firman y el 22,8 por cien de las mujeres. En 1675 partimos de una situación bastante precaria, sobre todo para el sexo femenino $(23,6$ por cien y 8,06 por cien

(12) B. BENNASSAR, "Las resistencias mentales...", op. cit., p. 155. 
de hombres y mujeres respectivamente) y, transcurrido un siglo, los porcentajes han variado, sobre todo entre la población femenina $(36,3$ por cien de hombres que firman y 25,8 por cien de mujeres). El crecimiento de la población alfabeta sigue en el último cuarto del siglo, al final del cual se consiguen las cifras del 45,4 por cien y 32,2 por cien para hombres y mujeres.

El mundo rural, como era de esperar, ofrece tasas más débiles. En Medina Sidonia, en 1675, firman el 14,7 por cien de los hombres, y entre la población testamentaria femenina el 96 por cien afirma no saber escribir y el 4 por cien restante es indeterminable. A mediados de la centuria siguiente, firman el 34,7 por cien de los hombres y el 15 por cien de las mujeres, mientras que en 1800 lo hace el 38,4 por cien de los testadores masculinos y el 44,4 por cien de los femeninos. Evolución positiva del número de testadores alfabetos, sobre todo entre las mujeres. En Alcalá de los Gazules, la situación de partida, en 1675, casi es idéntica a la situación de llegada: sólo en 1800 obtenemos un pequeño porcentaje de mujeres firmantes -el 5,26 por cien-, inexistente en los cinco anteriores años de la muestra, mientras que el de testadores que firma - 11,11 por cien- permanece en niveles parecidos a los de cien años antes (10,5 por cien de hombres que firman en 1675). Los porcentajes globales para el período - 12,3 por cien y 1,35 por cien de testadores masculinos y femeninos que firman - evidencian de forma clara el retraso del mundo rural en el acceso a la cultura escrita y la marginación de la mujer en este proceso, sobre todo por la situación tan desventajosa de la que partía.

A las diferencias entre medio rural y medio urbano y entre población masculina y femenina se unen, asimismo, otros desequilibrios que son consecuencia de la actividad profesional y los niveles de riqueza del grupo humano sometido a encuesta. Aunque sólo hemos podido clasificar profesionalmente a la mitad de la muestra, el número de testadores de los que poseemos datos sobre:su profesión (1080 entre las cuatro localidades) es suficientemente representativo y un buen reflejo de las sociedades a las que pertenecen. Como puede observarse en el cuadro que sigue, existe un fuerte contraste entre el medio urbano y el medio rural: el desarrollo de las actividades primarias en Medina y Alcalá tiene su contrapartida en el enorme peso del sector terciario en las dos poblaciones de la Bahía, sobre todo en Cádiz. Destaca, asimismo, la relativa presencia de este sector, aunque no a idénticos niveles que en las localidades citadas, en Medina Sidonia achacable, fundamentalmente, a la existencia de un nutrido grupo de eclesiásticos y personal dependiente de la Iglesia. Es necesario matizar también que aunque los comerciantes están bien representados en las cuatro poblaciones, oscilando los porcentajes entre el mínimo de 20,8 por cien de Alcalá de los Gazules y el máximo del 42 
- la firma en el testamento-

Hombres

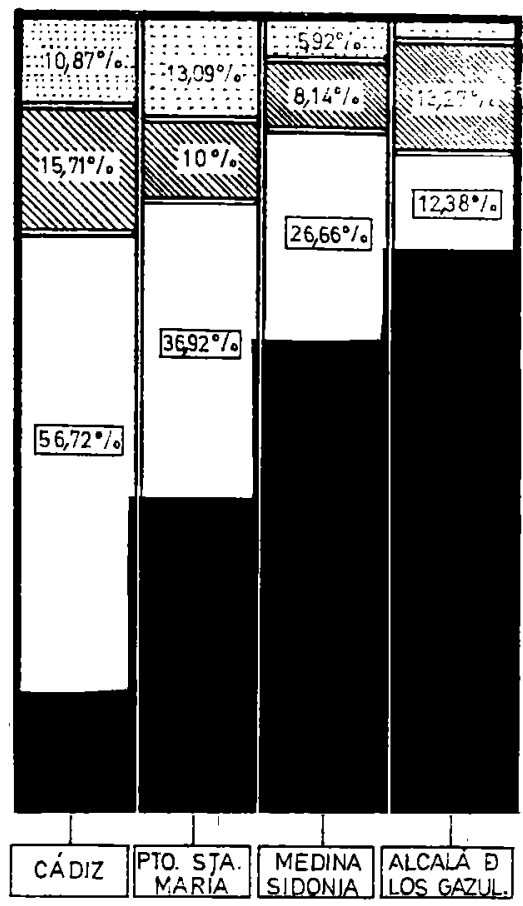

Ambos Sexos

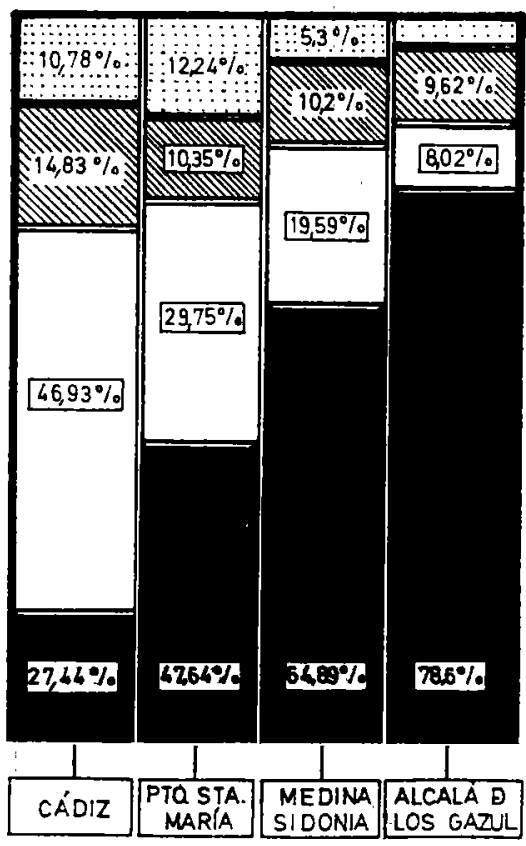

Mujeres

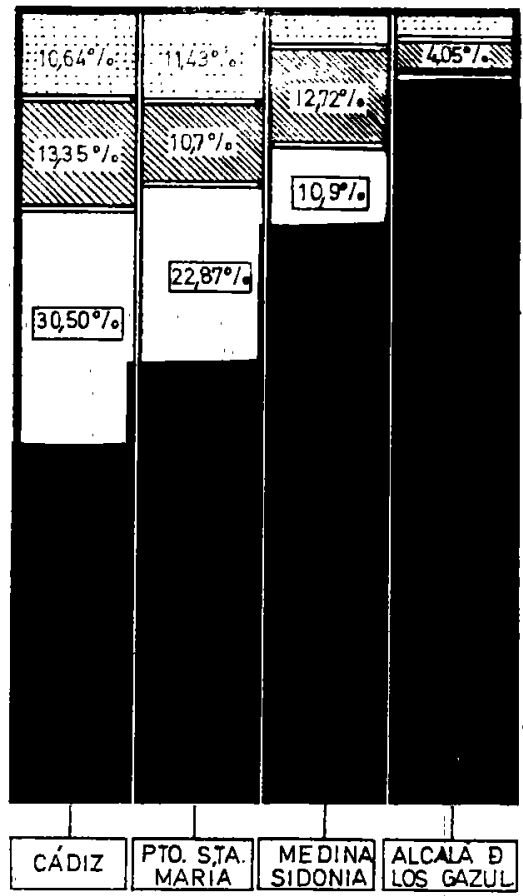

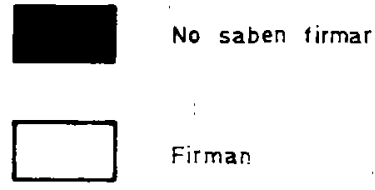
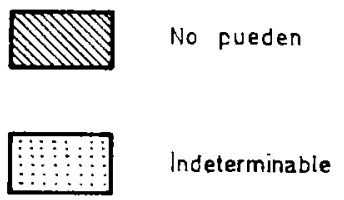


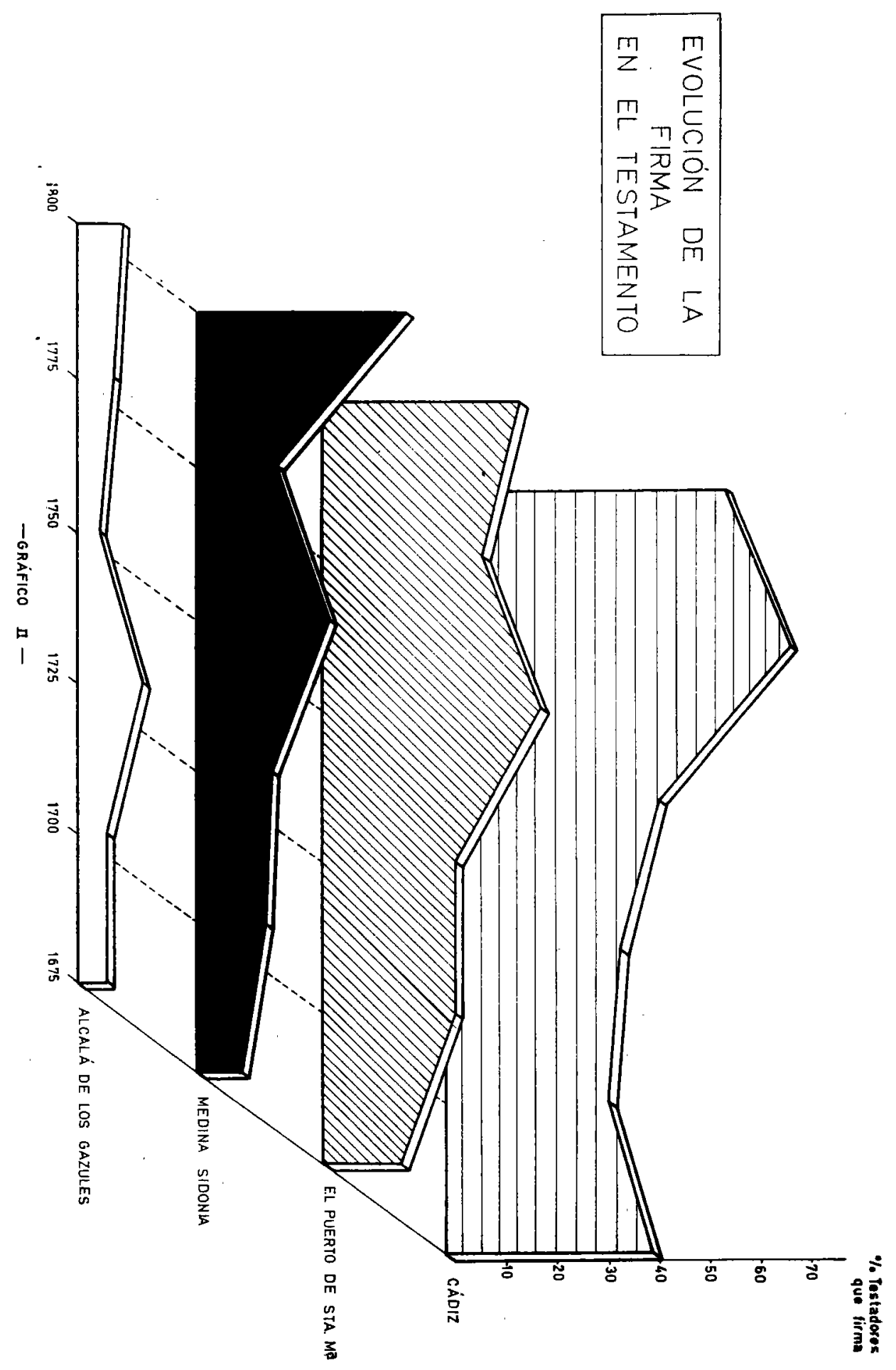


por cien en Cádiz, tanto en esta última localidad como en El Puerto de Santa María dentro de este grupo hay que destacar la existencia de importantes hombres de negocios dedicados fundamentalmente al comercio con Indias. El alto porcentaje de testadores clasificados dentro del epígrafe de "otros servicios" presente en Alcalá de los Gazules viene dado por el nutrido grupo de jornaleros de esta población.

\section{CUADRO I: CLASIFICACIÓN DE LA POBLACIÓN ENCUESTADA POR GRUPOS SOCIOPROFESIONALES}

\begin{tabular}{|c|c|c|c|c|c|c|c|c|c|}
\hline \multirow{3}{*}{ Actividades } & & \multicolumn{2}{|c|}{ CÁDIZ } & \multicolumn{2}{|c|}{$\begin{array}{c}\text { EL } \\
\text { PUERTO }\end{array}$} & \multicolumn{2}{|c|}{ MEDINA } & \multicolumn{2}{|c|}{ ALCALÁ } \\
\hline & & $\mathbf{N}$ & $\%$ & $\mathbf{N}$ & $\%$ & $\mathbf{N}$ & $\%$ & $\mathbf{N}$ & $\%$ \\
\hline & & & & & & & & & \\
\hline Primarias & & 1 & 0,15 & 56 & 28,18 & 69 & 55,2 & 94 & 74,01 \\
\hline Actividades & & & . & & & & & & \\
\hline Secundarias & & 65 & 10,3 & 25 & 12,6 & 7 & 5,6 & 9 & 7,08 \\
\hline & Prof. liberales & 22 & $3 ; 9$ & 6 & 5,12 & 3 & 6,1 & 1 & 4,1 \\
\hline & Iglesia & 47 & 8,3 & 13 & 11,1 & 17 & 34,6 & 3 & 12,5 \\
\hline Actividades & Admón. Civil & & & & & & & & \\
\hline Terciarias & y criminal & 175 & 31,02 & 31 & 26,4 & 5 & 10,2 & 2 & 8,3 \\
\hline & Comercio & 238 & 42,19 & 53 & 45,2 & 15 & 30,6 & 5 & 20,8 \\
\hline & Otros servc. & 82 & 14,53 & 14 & & & & & \\
\hline & & & & & 11,9 & 9 & 18,3 & 13 & 54,1 \\
\hline & $\begin{array}{l}\text { Total act. } \\
\text { Terciarias }\end{array}$ & & & & & & & & \\
\hline & & 564 & 89,52 & 117 & 59,09 & 49 & 39,2 . & 24 & 18,8 \\
\hline
\end{tabular}

Tras estos detalles que consideramos necesarios a fin de que se pueda efectuar una lectura real de los resultados, vamos a adentrarnos en el análisis de la firma siguiendo esta distribución socio-profesional. Este nos confirma el escaso nivel de alfabetización existente entre la población campesina en la que aparece el número más bajo de firmantes. Así se constata en Medina Sidonia y Alcalá de los Gazules, con un vecindario dedicado, casi en su mayoría, a las actividades primarias y así lo observamos también en El Puerto de Santa María. Como puede observarse con detalle en este cuadro, el porcentaje de testadores que asegura no saber escribir es bastante alto dentro del sector; el hecho adquiere mayor trascendencia si se tiene en cuenta que no incluye a la población jornalera, a la que hemos agrupado dentro de "otros servicios" en el sector terciario. 


\section{CUADRO II: LA FIRMA ENTRE LOS TESTADORES DEDICADOS A LAS ACTIVIDADES PRIMARIAS}

\begin{tabular}{lrrrr} 
& \multicolumn{2}{c}{ FIRMAN } & \multicolumn{2}{c}{ NO SABEN ESCRIBIR } \\
\cline { 2 - 5 } & MASC. & \multicolumn{1}{c}{ FEM. } & MASC. & \multicolumn{1}{c}{ FEM. } \\
\cline { 2 - 5 } El Puerto de Sta. M. ${ }^{2}$ & $20,51 \%$ & $\mathbf{1 8 , 7 5 \%}$ & $66,66 \%$ & $50 \%$ \\
Medina Sidonia & $19,56 \%$ & $14,28 \%$ & $69,56 \%$ & $71,42 \%$ \\
Alcalá de los Gazules & $11,47 \%$ & $3,03 \%$ & $77,04 \%$ & $90,90 \%$ \\
\hline
\end{tabular}

Por lo que se refiere al artesanado, los resultados nos lo hacen aparecer como un grupo heterogéneo. Si bien en las cuatro localidades las actividades secundarias siguen a las primarias en cuanto a bajo número de firmantes, los porcentajes varían según tomemos la muestra de Cádiz o la de El Puerto, Medina o Alcalá. En la capital gaditana es el 50 por cien de los artesanos el que firma su testamento, mientras en El Puerto de Santa María los que hacen lo propio constituyen el 22,7 por cien de la muestra. En Medina Sidonia los firmantes, al igual que en Cádiz, son el 50 por cien, pero entre la pequeña muestra de artesanos alcalaínos que poseemos, la mitad de ellos es incapaz de escribir su nombre y la otra mitad afirma no poder hacerlo por la gravedad de su estado de salud.

Los testadores englobados en el grupo de actividades terciarias son los que destacan por un mayor nivel de alfabetización. En Cádiz este grupo contiene a más del 60 por cien de firmantes — concretamente el 61,30 por cien-; en El Puerto de Santa María y Medina Sidonia los que saben firmar dentro del mismo se aproximan al 50 por cien -47 y 49 por cien respectivamente-, y también es "relativamente" alto (dentro de la debilidad del número de alfabetos para todos los grupos de Alcalá de los Gazules) - cerca del 20 por cien- en esta última localidad. No obstante, pensamos que el grupo de actividades terciarias posee una heterogeneidad suficiente como para que en él se produzcan fuertes desigualdades entre los distintos subsectores que lo constituyen. Así, el subgrupo de profesiones liberales y empleados, donde se incluyen abogados, escribanos y médicos, entre otros, arroja en las tres localidades de las que poseemos representación para este sector (Cádiz, El Puerto y Medina) porcentajes muy altos de alfabetización, que oscilan entre el 77 y el 100 por cien de testadores que saben escribir; cifra comparable, solamente, a la que ofrece otro subsector en el que presumiblemente el número de alfabetizados también era elevado, al menos para estas fechas: la Iglesia. Los miembros del estamento eclesiástico suministran, esta vez en las cuatro poblaciones, tasas de alfabetización comprendidas entre el 67 y el 100 por cien de la muestra.

Tenemos, así, un clero con un nivel de instrucción alto si conside- 
ramos la media de la época, puesto que todos sus miembros aparecen conociendo los rudimentos de la escritura y la lectura, y que además es el grupo que suministra un número mayor de personas que han realizado estudios superiores (son, generalmente, licenciados y doctores en teología). Esta es una realidad que parece común en España, al menos los estudios puntuales ya realizados apuntan en dicha dirección. Así sucede durante el siglo XVI en la región de Córdoba y en la de Toledo, según se deduce del análisis sobre procesos inquisitoriales realizados por M.C. Rodríguez:y B. Bennassar (13), y en la Sevilla del siglo XVIII en la que J.A. Rivas Alvarez, a partir de documentación testamentaria, subraya el alto índice de alfabetización que ofrece el clero - próximo en este caso al 100 por cien- (14). A la misma conclusión llega M. Ventura i Munné tras el estudio de una serie de testamentos de los años 1750-54, pertenecientes a la localidad catalana de Mataró (15).

En el tercer subsector considerado dentro de las actividades terciarias: profesionales de la administración civil y militar, de la navegación comercial y de guerra, la media de alfabetización baja con respecto a los grupos anteriores, aunque todavía seguimos encontrándonos en niveles razonables que oscilan entre el 42 por cien que se obtiene en El Puerto de Santa María y el 67 por cien de Medina Sidonia (la tasa de Cádiz está muy próxima a la de Medina con un 63 por cien de firmantes). Es preciso hacer notar que este grupo está integrado por elementos que ocupan status muy diferentes y que han recibido también, presumiblemente, una educación muy distinta. No es lo mismo un comisario de guerra de marina o un teniente coronel que un soldado; ni un magistrado que un marinero. Son, sin duda, estos últimos escalafones, englobados bajo el epígrafe de tropa pagada, los que hacen caer la media.

En lo que se refiere a los comerciantes, los resultados ya no son tan homogéneos, geográficamente hablando, como para los grupos anteriores. Aparecen mayoritariamente alfabetizados en Cádiz -72 por cien-, donde la muestra cuenta con un importante número de hombres de negocios, nacionales y extranjeros, dedicados al tráfico con Indias, y con unos niveles medios en El Puerto de Santa María - 53,5 por cien-, donde también son localizables, aunque en menor proporción, negociantes de la Carrera de Indias. En Medina Sidonia este subsector está formado, en su mayoría, por pequeños comerciantes, y la media desciende considerablemente respecto a los grupos precedentes, situándose en el 28,5

(13) Idem.; "Signatures et niveau culturel...», op. cit., p. 23.

(14) Miedo y Piedad: testamentos sevillanos del siglo XVIII, Sevilla, 1986, p. 65

(15) “El nivell d’alfabetizació de la població de Mataró a mitjan del segle XVIII». Actas I Congrés d'Historia Moderna de Catalunya, vol. 2, Barcelona, 1984, p. 617. 
por cien; mientras en Alcalá de los Gazules no firma la escasa representación del comercio que existe en nuestra muestra.

El último subgrupo a considerar es el que denominamos «Otros Servicios". Están contemplados aquí el servicio doméstico, mozos y mandaderos, peluqueros, cómicos y gentes del teatro, carboneros y aguadores, y, en el mundo rural, los jornaleros. En Cádiz es este el grupo que hace bajar la media en las actividades terciarias, puesto que de unos niveles que se situaban alrededor del 70 por cien para otras actividades, se desciende en éste al 47 por cien. No así en El Puerto de Santa María y en Medina donde los porcentajes de firmantes son, para este sector, semejantes a los obtenidos para el comercio: en El Puerto alrededor del 50 por cien y en Medina del 25 por cien. Es este último, también, un grupo tan vario que la generalización no es deseable. Aun dentro del servicio doméstico tendríamos que distinguir entre aquellos trabajadores que desempeñan su función en grandes casas - mayordomos, administradores o secretarios- quienes presumiblemente gozan de un nivel de instrucción al menos primario, y aquellos dedicados a labores mucho más humildes - recaderos, mozos de cuadra, etc. .

Concluyendo, el nivel de alfabetización está en estrecha relación con la posición socioprofesional que cada grupo tiene en la sociedad, y en este sentido aquellos elementos que disfrutan de un status más elevado son los más alfabetizados. Existen, además, otros grupos a los que la propia profesión en la que se ejercitan exige este nivel de conocimientos mínimos. Así, profesiones liberales, grandes y medianos comerciantes y funcionarios letrados ofrecen, asimismo, unos porcentajes de alfabetización altos (entre el 70 y el 100 por cien).

Entre la población artesana, en la que de igual forma habría que distinguir numerosos subgrupos que podrían ir desde las artesanías de lujo, con abundante presencia en el Cádiz del Setecientos - plateros o artífices del oro, relojeros, ebanistas, etc.- que, generalmente, saben leer y escribir, de otros oficios como zapateros, tintoreros, panaderos..., entre los que el nivel de instrucción desciende, los porcentajes varían entre el 25 y el 50 por cien.

Finalmente, los trabajadores de la tierra estarían en situación mucho menos ventajosa, reduciéndose entre ellos el tanto por ciento de firmantes a cifras comprendidas entre el 10 y el 20.

Desequilibrios en función del sexo (el porcentaje de analfabetismo es mayor entre las mujeres que entre los hombres en las cuatro poblaciones), en función del grado de urbanización (el número de alfabetos desciende conforme nos alejamos de los núcleos más urbanizados y nos aproximamos a zonas rurales) y desequilibrios en relación con la posición socioprofesional de los grupos en cuestión. 
De 2446 testadores (otorgantes de 2351 testamentos), sólo firman 917, es decir el 39 por cien. Sin embargo, y según ya hemos tenido ocasión de ir comprobando, estos datos globales poco nos dicen de la evolución positiva que se registra entre las dos fechas límites de nuestro estudio (1675 y 1800). Un análisis de los resultados en la diacronía revela una modificación sustancial de la situación de partida, realizada, sobre todo, en la segunda mitad del Setecientos. Entre 1675 y 1775 el número de firmantes se ha duplicado en El Puerto de Santa María y en Medina Sidonia (del 15 al 31 por cien en la primera localidad y del 8,4 al 14,8 por cien en la segunda) y también ha aumentado significativamente en Cádiz (del 40 al 69 por cien), mientras la población de Alcalá de los Gazules sigue prácticamente estancada en idénticas tasas de alfabetización (del 5 al 7 por cien). Este crecimiento, preciso es señalarlo, afecta a ambos sexos, y en algunos casos como en Cádiz y El Puerto de Santa María casi se corrigen los tradicionales desequilibrios entre firmantes masculinos y femeninos, de forma que a finales del siglo XVIII la distancia entre población alfabeta femenina y masculina es mucho menor que a finales del siglo anterior. En cualquier caso, y a pesar de esta evolución positiva, no parece que en Cádiz capital ni tampoco en El Puerto de Santa María el nivel de alfabetización cubra las expectativas que de la propia estructura demográfica, económica y social de estas poblaciones podría deducirse.

C.M. Cipolla, recogiendo la división de Fleury y Valmary (con base a los datos de la encuesta Maggiolo de finales del XIX) de dos áreas culturales en Francia, una más instruida al norte de una línea imaginaria que uniría la bahía del Monte Saint-Michel al lago de Ginebra, establece una división entre la Europa del Norte y la del Sur aventurando el porcentaje de 45-35 por cien de alfabetos para la población de la Europa protestante y del 30-15 por cien para la Europa católica, en el último cuarto del siglo XVII (16). Siguiendo estas estimaciones globales y para estas mismas fechas, Cádiz sobrepasaría ligeramente estas tasas $-40,54$ por cien-, aproximándose al nivel de la Europa más alfabetizada, y El Puerto de Santa María -15,38 por cien- estaría en el de la Europa Católica. Medina Sidonia y Alcalá de los Gazules presentan porcentajes marcadamente inferiores. Sin embargo, si contrastamos nuestros resultados con los que obtiene M. Vovelle para la Provenza del siglo XVIII, relacionando directamente alfabetización con grado de urbanización (17),

(16) C.M. CIPOLLA, op. cit., pp. 68-72.

(17) $\mathrm{M}$. VOVELLE, "Y a-t-il une révolution culturelle au XVIII e siècle? A propos de l'éducation populaire en Provencei, Revue d'Histoire Moderne et Contemporaine, "Gen.-mar., 1975), pp. 89-141. 
observamos que son más bajos en nuestras cuatro localidades. Cádiz, con más de 40.000 habitantes a comienzos del siglo XVIII, apenas alcanza el 50 por cien de alfabetos localizable en Marsella y Avignon, si bien en 1775 la situación ha variado notablemente y el 75,7 por cien de firmantes masculinos y el 56,8 por cien de femeninos pueden considerarse bastante normales. El Puerto de Santa María y Medina Sidonia ofrecerían, a finales del Setecientos, porcentajes bastante aceptables para el sexo femenino - 32,2 por cien y 44 por cien de firmantes- y algo bajos para el masculino. Los índices de Alcalá, aun a finales del siglo XVIII, no resisten la comparación.

El contraste con el panorama español del Setecientos no se revela muy agudo, aunque las tasas de Cádiz son ligeramente más bajas que las obtenidas para Sevilla en 1701 (18) y en Málaga entre 1700 y 1724 (19). A finales de siglo Cádiz se ha recuperado, porque si Sevilla sigue superando ligeramente sus tasas (20) ofrece, en cambio, un porcentaje más alto de población alfabeta que Córdoba (21).

No obstante estas diferencias apreciables entre los niveles de población alfabeta de Cádiz y los de las tres ciudades andaluzas de las que poseemos datos, creemos que es mucho más interesante subrayar los propios contrastes existentes en el seno de nuestra muestra. El sexo femenino se apunta como condicionamiento negativo a la hora de acceder a los primeros rudimentos de la cultura escrita. En las cuatro localidades en las que hemos efectuado esta prospección a través de la población testamentaria, el porcentaje de mujeres firmantes es siempre inferior al de los hombres. También el status profesional condiciona el nivel de alfabetización según hemos podido ver, pero, con ser importantes estas re-

(18) J.A. RIVAS ALVAREZ, utilizando, asimismo, la fuente testamentaria ofrece las cifras del 52,54 por cien de firmantes, que coresponden a un 67,36 por cien de firmantes varones y el 38,41 por cien de las mujeres. Ambas son superiores a las obtenidas en Cádiz para $1700-45,9$ por cien de hombres que firman y 20,5 por cien de mujeres-; ello puede venir motivado por una mayor difusión en esta última ciudad del testamento entre medios más populares, en op. cit., p. 45.

(19) M. REDER GADOW sitúa la tasa de alfabetización, para ambos sexos, en el 50,7 por cien, Morir en Málaga. Testamentos malagueños del siglo XVIII, Málaga, 1986, p. 153.

(20) J.A. RIVAS obtiene para 1799 el 85 por cien y el 62,63 por cien del hombres y mujeres que firman, en op. cit., p. 83.

(21) S. GÓMEZ NAVARRO para 1790-1814 sostiene que firma el 52,04 por cien del conjunto de sus testadores, en "El sentido de la muerte y la religiosidad a través de la documentación notarial cordobesa (1790-1814)». I. Análisis y estudio de los testamentos, Boletín del Ilustre Colegio Notarial de Granada, n. ${ }^{\circ}$ 6, Granada, 1985, p. 74. 
laciones, existe, desde nuestro punto de vista, una más directa que agrava las dos anteriores, a saber, el grado de urbanización. Es Alcalá de los Gazules, la población con menor número de habitantes - unos 4.000 en la segunda mitad del XVIII-, con una mayor dependencia del sector primario y una más débil presencia de actividades relacionadas con el terciario, la que ofrece porcentajes de alfabetización más bajos y mayores contrastes entre los dos sexos - al respecto, ese 1,31 por cien de mujeres alfabetas es bastante representativo-. Al contrario, los niveles obtenidos en Cádiz son suficiente exponente de la incidencia en estos aspectos de una diversificación de las actividades económicas y, paralelamente, de una abundante población en crecimiento. Pero, además, en el medio rural se aprecia con menor nitidez la evolución positiva constatable a lo largo del siglo en Cádiz, El Puerto de Santa María e incluso en Medina, de forma que, también en lo que atañe a la difusión de la cultura escrita, sufre un retraso respecto de la ciudad. Esta aparece, una vez más, como el ambiente más propicio para la libertad y la cultura. 